Review

\title{
Does the Measles Virus Contribute to Carcinogenesis? - A Review
}

\author{
Daniel Benharroch¹, Jacob Gopas², Samuel Ariad ${ }^{凶}$ \\ 1. Department of Pathology; \\ 2. Department of Oncology, Soroka University Medical Center and Faculty of Health Sciences, Ben-Gurion University of the Negev, \\ Beer-Sheva, Israel. \\ $\square$ Corresponding author: Prof. Daniel Benharroch, M.D., 972-8-6400920; fax: 8-6232770; e-mail: benaroch@bgu.ac.il.
}

( ) Ivyspring International Publisher. This is an open-access article distributed under the terms of the Creative Commons License (http://creativecommons.org/ licenses/by-nc-nd/3.0/). Reproduction is permitted for personal, noncommercial use, provided that the article is in whole, unmodified, and properly cited.

Received: 2013.08.16; Accepted: 2013.12.06; Published: 2014.01.05

\begin{abstract}
An association between the measles virus and classical Hodgkin lymphoma has previously been suggested by us. This has been refuted by two European groups. A reevaluation of the arguments held against our thesis was carried out and further evidence for a relationship between the measles virus and additional solid tumors has been presented. We have suggested a molecular mechanism to support a possible contribution of the virus to carcinogenesis in classical Hodgkin lymphoma.
\end{abstract}

Key words: measles virus; Hodgkin lymphoma; lung cancer; breast cancer; apoptosis.

\section{Introduction}

In 2004, we presented evidence for an association between classical Hodgkin lymphoma (cHL) and the expression of measles virus (MV) antigens with the presence of MV-RNA by reverse transcriptase-polymerase chain reaction and in situ hybridization in tumor tissues (1). At that time, we had no proof of a causal relationship between the cancer and the virus.

Three years later, our view on the association between $\mathrm{CHL}$ and MV was disputed by two European groups $(2,3)$. However, since their methodology and more specifically the high level of selection used by these researchers were different from ours, we believed that we had a mandate to explore further the issue. We therefore searched for a similar association to that described between $\mathrm{cHL}$ and $\mathrm{MV}$ in various solid cancers (4-6).

Turning back to $\mathrm{CHL}$ and MV, we investigated apoptosis modulation as a possible mechanism of action for MV in cancers, perhaps approaching a hint for causality (7).

\section{Original Substantiation}

Considering the linkage between microbes and cancer in other animals, one is surprised to observe that only about $20 \%$ of human cancers are thought to arise by mechanisms which involve viruses, bacteria and parasites (8). Evidence for involvement of these organisms in cancer comes partly from their detection in biopsies and partly from animal and epidemiological investigations $(1,9)$. The biologic agent is usually responsible for only a limited number of steps in the initiation or the progression of the malignancy (10, 11). Often, the precise role of cancer-associated biologic agents is hard to decipher, due to the long delay from initial infection and to further compounding effects. Viruses as well as other organisms probably act therefore in conjunction with additional carcinogenic factors (10).

Biological organisms may generate a chronic-type inflammation $(9,12)$, but the latter may also be due to other causes. In some cases of unresolved chronic inflammation, the immune response becomes maladaptive, promoting tumorigenesis (12). Moreover, a regenerative process supported by several bio- 
active mediators promotes cell survival, tissue remodeling and angiogenesis. The mediators also cause genomic stress and mutations (12). Hence an association of chronic inflammation with cancer is being established.

Classical Hodgkin lymphoma has been our research topic of predilection for several years, in spite of the fact that so much appears to be known about it. This is a cancer of lymph nodes and more precisely of the immune system. Although infrequent, it is one of the most frequent cancers of young adults (15-34 years). Often, the tumor cells in cHL represent a small minority among the cellular population in the tumor mass. Unrelated to the latter, very good responses to treatment are obtained $(80 \%$ of patients and more are cured) (13).

An association between cHL and Epstein-Barr virus (EBV) was described several decades ago $(1,13$, $14-16)$. This link varies from $17 \%$ in some industrialized countries to near $100 \%$ in a few developing countries. This virus expression varies with gender, more likely to be positive in male patients. Epstein-Barr virus expression varies also with cHL histological subtype: mixed cellularity - 32-96\% and nodular sclerosis $-10-50 \%(17,18)$.

The pathogenesis of EBV-related cHL evolves around nuclear factor-kB (NF-kB) activation which may induce cell proliferation, inflammation and apoptosis arrest. In addition, the EBV/LMP1 protein has a BCL-2-like effect and causes apoptosis resistance $(19,20)$.

In the association of $\mathrm{CHL}$ with $\mathrm{EBV}$, combining the three (21) with the four cHL models (16), we obtain four EBV status-related age curves. The first includes children, mostly EBV+ males with mixed cellularity HL. The largest curve categorizes young adults, with a high proportion of females, mostly EBV-negative and nodular sclerosis HL. Within this curve is a much smaller one representing young adult males EBV+, who have overcome infectious mononucleosis. The last curve features older adults, mainly with EBV+ disease and mixed cellularity cHL.

Thus EBV+ cases in industrialized countries may account for a small part only of cHL. Young adult patients, mainly women, who are those most expected, according to well documented epidemiological studies, to be related with late exposure to a common infectious agent, have the lowest association with EBV $(16,22-26)$.

None of the additional viruses considered so far as possible candidates have been found in a consistent manner in cHL tissues (cited in 1).

In 2002, one of the present authors (AS) suggested the possible candidacy of the measles virus in its association with cHL, mainly in the young adult subset. This link was proposed on the basis of the following traits of the MV. Measles virus is lymphotropic, showing also tropism for the oropharyngeal epithelium. The acute measles infection is followed as a rule by a transient cellular immune deficiency, in spite of a lifelong protective immunity. Polykaryons may be evident in the infected tissues (27). Since 1963, following anti-MV vaccination, measles infection has occurred more often after age $5(28,29)$.

We have therefore proposed MV as a possible biologic agent associated with $\mathrm{CHL}$, at least in young adult patients.

In our study, published in 2004, we described 154 biopsies from untreated cHL patients. We used immunohistochemistry with the avidin-biotin peroxidase complex method. We performed in addition, RT-PCR on total RNA obtained from frozen or formalin-fixed, paraffin-embedded cHL tissues. The products of nested PCR were used for a Southern blot. Last, in situ hybridization was carried out according to Ogata et al (cited in 1).

Eighty two of the 154 biopsies (54\%) were positive for two MV antigens or more. As demonstrated by the Southern blot, 4 of 15 hemagglutinin MV-RNAs and 2 of 16 nucleoprotein MV-RNAs were positive. By ISH 2 of 7 hemagglutinin MV-RNAs and 8 of 21 nucleoprotein MV-RNAs were positive (1).

We characterized clinical and biological features of cHL as they compare with positive and negative MV expression. We found a preferential association of MV-positivity with female gender $(p=.036)$, with nodular sclerosis as opposed with mixed cellularity cHL subtypes ( $\mathrm{p}=.0013)$. CD15 expression was associated with a negative MV expression (1).

As MV expression did not exclude that of EBV, we looked for clinical correlations with $\mathrm{MV}+/ \mathrm{EBV}-$ and with $\mathrm{MV}-/ \mathrm{EBV}+$. We found an association between MV+/EBV- and nodular sclerosis $(p=.00008)$, with early stages $(p=.023)$ and with an apoptotic index of lower than median $(p=.024)(1)$.

A multivariable logistic regression model of prognostic factors with dying of cHL (89 patients) confirmed that high tumor stage was an independent prognostic factor. It also showed that $\mathrm{MV}+/ \mathrm{EBV}$ - was also a negative independent prognostic factor, $\mathrm{OR}=10.05(95 \% \mathrm{CI}-.98-103.7, \mathrm{p}=.05)$ and that MV-/EBV- was also a negative independent prognostic factor, $O R=15.2(95 \% \mathrm{CI}-1.05-220.3 ; \mathrm{p}=.04)(1)$.

The conclusion of this part of the research was that we had found an association between the presence of MV and cHL. This supported epidemiological evidence on the incidence of brain and spinal cord tumors as well as of cHL following exposure to MV around the time of birth $(30,31)$. Our findings were also consistent with reports on sporadic HL regres- 
sion after measles infection or vaccination (32-35). In addition, childhood infections, notably including measles, were shown to protect from the occurrence of cHL (36).

In spite of finding more female patients, more nodular sclerosis subtype, and more patients with early stages in cases of $\mathrm{MV}+\mathrm{cHL}$, it unexpectedly appears that these patients had a worse prognosis. The longest survival seemed to be related with the positive expression of both MV and EBV in the tumor cells.

At this stage, these descriptive findings allowed no determination of causality in the relationship between MV and cHL. They seemed to elicit no obstacle to the use of the vaccination strains of the measles virus for prevention.

\section{The German Connection}

In an attempt to confirm or disprove our data, Küppers et al selected 18 of 44 of their own cHL fresh frozen tissues for their very high RNA quality and for their excellent Hodgkin-Reed-Sternberg morphology (2). They used UV-laser beam single cell microdissection. About 100 cells were pooled for each experiment. RNA was extracted and RT-PCR performed on primers from three MV genes. The 18 German cases did not show evidence of any of the 3 viral transcripts. The GAPDH housekeeper gene showed high content of RNA. In addition, 4 HL-related cell lines were also negative for the MV transcripts (2).

\section{The Israeli Connection}

We sent 22 of our fresh-frozen cHL tissues to Germany, chosen for their positive immunohistochemical expression of MV antigens. But only 7 were selected, according to the Küppers et al stringent criteria mentioned above.

The seven cases were found by Küppers et al to be negative for the various MV transcripts studied (2).

Before giving up our research, we critically evaluated the different results, acknowledging the fact that we had agreed to take part in the publication by Küppers et al (2).

It now appeared that Küppers et al were extremely selective in choosing the cases to be included in their study. In addition, we believe that cHL tissues probably show low abundance RNA, mainly due to their high content of ribonucleases in eosinophil-rich cHL cases (13). As a consequence, GAPDH which shows as a rule abundant RNA in tissues examined is most certainly an inadequate housekeeping gene for this specific experiment (37). Moreover our 7 cases sent to Germany were all mixed cellularity cHL and most were EBV+ cases. Of these we had studied 5 cases for MV-RNA, 2 of which were faint and three - negative. In addition, one should be extremely cautious when comparing Israel to Germany regarding measles. In Israel, the population has been subject to frequent outbursts of measles and it has shown a steady increase in the incidence of young adult cHL (38). Finally, the measles virus phosphoprotein has been described as an inhibitor of the ubiquitination and stabilization of hPIRH2, an ubiquitin E3 ligase, one of the regulators of the p53 pathway (39). This finding may be relevant to the issue of a putative role for MV in carcinogenesis.

\section{Recent Evidence: Measles Virus Associa- tion with Other Cancers}

\section{Endometrial carcinoma and the measles virus}

We studied 49 endometrial carcinoma (EC) cases, 36 with known follow-up. Twenty of the 36 patients (72\%) expressed MV antigens in the tumor cells, mainly of EC type I. Sixteen of 21 were positive for MV-RNA by in situ hybridization. When EC type II was allied with MV expression, deeper myometrial invasion and a higher mortality were evident (4).

\section{Lung cancer and measles virus antigens expression}

Lung cancer cells have been found to over-express PIRH2, an ubiquitin E3 ligase, which may inactivate p53 (40).

We described 65 non-small cell lung cancers. Fifty four of the 65 were positive for MV antigens. This positive expression is associated with older patient age, positive PIRH2 expression as well as with improved survival (5). The expression of MV proteins may signify inhibition of the functions of PIRH2, as mentioned above (39).

\section{Breast cancer and the measles virus}

We studied 131 cases of invasive ductal carcinoma. Sixty-four percent of these were positive for MV antigens by immunohistochemistry. MV antigens expression was associated with ER $(\mathrm{p}=.018)$; with Ki-67 $<40 \%(\mathrm{p}=.029)$; with low or intermediate grade $(p=.037)$; with age $<50 \quad(p=.039)$ and with $p 53$ over-expression $(\mathrm{p}=.049)$.

A multivariate logistic regression showed an association between $\mathrm{MV}$ expression and grade $(p=.011) ; p 53$ expression $(p=.03)$ and age $(p=.041)$.

We concluded that we have found evidence of MV antigens expression in a large proportion of the breast cancers studied. MV expression was associated with younger age, lower histologic grade and p53 over-expression and suggests it may play a role in the development of breast cancer (6). 


\section{Preliminary results on melanoma and measles virus}

Using immunohistochemistry, melanoma expressed nucleoprotein-MV in 46 of 56 cases, but benign nevi expressed this antigen in $23 / 24$. On the other hand, melanoma expressed the P- protein of MV in $19 / 55$ cases only.

\section{Are there measles virus-negative cancers?}

The 25 non-Hodgkin lymphomas tested (1) were negative for MV antigens. But ALK1-positive anaplastic large cell lymphomas were positive. Seminomas showed a high background of staining, but no clear positivity for MV antigens. Glioblastomas and mesotheliomas did not express MV antigens (Ariad S., personal communication).

Merkel cell tumor, hepatocellular carcinoma, malignant mixed mesodermal tumor and desmoids tumors are probably negative for these antigens.

\section{May the Measles Virus Play a Role in Carcinogenesis?}

While reviewing the role of apoptosis in Hodgkin-Reed-Sternberg (HRS) cells of cHL, in the light of conflicting evidence, we found that HRS cells showed inhibition of apoptosis in 55\% of the 217 studied cases only (7). In contrast with the consensus view, it is also suggested that NF-kB activation and EBV/LMP1 expression do not correlate with apoptosis arrest. We emphasized a negative correlation of p53 with a high apoptotic index $(\mathrm{p}=.001)(7)$.

We analyzed the link between positive MV expression and apoptosis-related factors and found it related with the apoptotic index less than median $(p=.005)$; with MDM-2 $(p=.028)$ and with IкB $(\mathrm{p}=.0001)$.

Viruses are known for their propensity to modulate the host cell apoptotic mechanisms. We suggest that the modulation of apoptosis may be one modus operandi of MV in CHL, perhaps supported by the inhibition of PIRH2 functions $(7,39,41)$.

\section{Conclusion}

In the first 9 months of 2011, 26,000 new cases of measles were reported by the WHO in Western Europe, together with 9 deaths and 7,288 hospitalizations (42). Ninety percent of these cases were adolescents and adults without vaccination or with an inadequate one. Comeback of measles to Europe is strongly feared.

We suggest that the above observed rise in measles, as it may not be recent, be related with the reported increase in incidence in young-adult $\mathrm{cHL}$ in Connecticut (43), Israel (38) and Quebec (44). The measles virus may indeed be the common contagious agent considered to evoke a late exposure infection and suspected to be a novel cause for CHL. It may also contribute to carcinogenesis in other solid tumors.

Further research is therefore called for to substantiate the above findings and suggest a therapeutic modality based on the proposed association.

\section{Acknowledgements}

We thank Kibbutz Sde-Boker, Israel, for its support.

\section{Competing Interests}

The authors have declared that no competing interest exists.

\section{References}

1. Benharroch D, Shemer Avni Y, Myint Y-Y, Levy A, Mejirovsky E, Suprun I, Shendler Y, Prinsloo I, Ariad S, Rager-Zisman B, Sacks M, Gopas J. Measles virus: evidence of an association with Hodgkin's disease. Brit J Cancer. 2004;91:572-9.

2. Maggio E, Benharroch D, Gopas J, Dittmer U, Hansmann M-L, Küppers R. Absence of measles virus genome and transcripts in Hodgkin-Reed/Sternberg cells of a cohort of Hodgkin lymphoma patients. Int J Cancer. 2007;121:448-53.

3. Wilson KS, Freeland JML, Gallagher A, Cosby SL, Earl JAP, Alexander FE, Taylor GM, Jarrett RF. Measles virus and classical Hodgkin lymphoma: No evidence for a direct association. Int J Cancer. 2007;121:442-7.

4. Benharroch D, Klinkovich I, Piura B, Shaco-Levy R, Gopas J. Evidence of measles virus antigens and RNA in endometrial cancer. Eur J Obstet Gynecol Reprod Biol. 2009;147:206-9.

5. Sion-Vardy N, Lasarev I, Delgado B, Gopas J, Benharroch D, Ariad S. Measles virus: evidence for association with lung cancer. Exp Lung Res. 2009;35:701-12.

6. Ariad S, Milk N, Bolotin A, Gopas J, Sion-Vardy N, Benharoch D. Measles virus antigens in breast cancer. Anticancer Res. 2011;31:913-20.

7. Benharroch D, Einav I, Feldman A, Levy A, Ariad S, Gopas J. Apoptosis of Hodgkin-Reed-Sternberg cells in classical Hodgkin lymphoma revisited. APMIS. 2010:118:339-45.

8. Boccardo E, Villa LL. Viral origin of human cancer. Curr Med Chem. 2007;14:2526-39.

9. Kremsdorf D, Soussan P, Paterlini-Brechot P, Brechot C. Hepatitis B virus-related hepatocellular carcinoma: paradigms for viral-related human carcinogenesis. Oncogene. 2006;25:3823-33.

10. Thorley-Lawson DA, Gross A. Mechanism of disease: persistence of Epstein-Barr virus and the origin of the associated lymphomas. N Engl J Med. 2004;350:1328-37.

11. Peek RM, Crabtree JE. Helicobacter infection and gastric neoplasia. J Pathol. 2006;208:233-48.

12. Tlsty TD, Coussens LM. Tumor stroma and regulation of cancer development. Annu Rev Pathol. 2006;1:119-50.

13. Benharroch D, Shemer-Avni Y, Levy A, Myint YY, Ariad S, Rager B, Sacks M, Gopas J. New candidate virus in association with Hodgkin's disease. Leukemia \& Lymphoma. 2003;44:605-10.

14. Knecht H, Berger C, Rothenberg S, Odermatt BF, Brousset P. The role of Epstein-Barr virus in neoplastic transformation. Oncology. 2001;60:289-302.

15. Niedobitek G, Meru N, Delecluse HJ. Epstein-Barr virus infection and human malignancies. Int J Exp Pathol. 2001;82:149-70.

16. Jarrett RF. Viruses and Hodgkin lymphoma. Ann Oncol. 2002;13(Suppl):23-9.

17. Jarrett RF, Armstrong AA, Alexander E. Epidemiology of EBV and Hodgkin lymphoma. Ann Oncol. 1996;7(suppl):5-10.

18. Chang KL, Albujar PF, Chen YY, Johnson RM, Weiss LM. High prevalence of Epstein-Barr virus in Reed-Sternberg cells of Hodgkin disease occurring in Peru. Blood. 1993;81:496-501.

19. Bargou RC, Emmerich F, Krappmann D, Bommert K, Mapara MY, Arnold W, Royer HD, Grinstein E, Greiner A, Scheidereit C, Dorken B. Constitutive nuclear factor-kappaB-RelA activation is required for proliferation and survival of Hodgkin's disease tumor cells. J Clin Invest. 1997;100:2961-9.

20. Izban KF, Ergin M, Huang Q Oin JZ, Martinez RL, Schnitzer B, Ni H, Nokoloff BJ, Alkan S. Characterization of NF-kappaB expression in Hodgkin disease. Mod Pathol. 2001;14:297-310.

21. MacMahon, B. Epidemiology of Hodgkin's disease. Cancer Res. 1966;26:1189-201.

22. Gutensohn N, Cole P. Childhood social environment and Hodgkin's disease. N Engl J Med. 1981;304:135-40.

23. Glaser SL. Spacial clustering of Hodgkin's disease in the San Francisco Bay area. Am J Epidemiol. 1990;132(1 Suppl):s167-s177. 
24. Westergaard T, Melbye M, Pedersen JB, Frish M, Olsen JH, Andersen PK. Birth order, sibship size and the risk of Hodgkin's disease in children and young adults: a population based study of 31 million person-years. Int J Cancer. 1997;72:977-81.

25. Sleckman BG, Mauch PM, Ambinder RF, Mann R, Pinkus GS, Kadin ME, Sherburne B, Perez-Atayde A, Thior I, Mueller N. Epstein-Barr virus in Hodgkin's disease: correlation of risk factors and disease characteristics with molecular evidence of viral infection. Cancer Epidemiol Biomarkers Prev. 1998;7:1117-21.

26. Glaser SL, Clarke CA, Nugent RA, Stearns CB, Dorfman RF. Social class and risk of Hodgkin's disease in young adult women in 1988-94. Int J Cancer. 2002;98:110-7.

27. Knipe DM, Howley PM, Griffin DE. Fields Virology, $5^{\text {th }}$ ed. Philadelphia: Wolters Kluwer/Lippincott, Williams and Wilkins Publishers. 2007.

28. Veit BC, Schyldower M, McIntyre S, Simmons D, Lampe RM, Fearnow RG, Stewart J. Serological response to measles vaccination in a highly immunized military dependent adolescent population. J Adolesc Health. 1991;12:273-8.

29. Desai VK, Kapadia SJ, Kumar P, Nirupam S. Impact assessment of mass measles vaccination. Ind J Pediat. 2002;69:1037-40.

30. Dickinson HO, Nyari TA, Parker L. Childhood solid tumors in relation to infections in the community in Cumbria during pregnancy and around the time of birth. Br J Cancer. 2002;87:746-50.

31. Tyari TA, Dikinson HO, Parker L. Childhood cancer in relation to infections in the community during pregnancy and around the time of birth. Int J Cancer. 2003;104:772-7.

32. Zygiert Z. Hodgkin's disease: remission after measles. Lancet 1971;1(7699):593.

33. Mota HC. Infantile Hodgkin's disease: remission after measles. Br Med J. 1973;2:241.

34. Zwitter M. Hodgkin's disease: therapeutic role of measles vaccine. Am J Med. 1984;77:49-64.

35. Schattner A. Therapeutic role of measles vaccine in Hodgkin's disease. Lancet. 1984;1(8369):171.

36. Alexander FE, Jarrett RF, Lawrence D, Armstrong AA, Freeland J, Gokhale DA, Kane E, Taylor GM, Wright DH, Cartwright RA. Risk factor for Hodgkin's disease by Epstein-Barr status: prior infections by EBV and other agents. Br J Cancer. 2000;82:1117-21.

37. Stals A, Mathijs E, Baert L, Botteldoorn N, Dessayer S, Mauroy A, Scipioni A, Daube G, Dierick K, Herman L, Van Coillie E, Thiry E, Uytendaele M. Molecular detection and genotyping of noroviruses. Food Environ Virol. 2012;4:153-67.

38. Ariad S, Lipshitz I, Benharroch D, Gopas J, Barchana M. A sharp rise in the incidence of Hodgkin's lymphoma in young adults in Israel. Isr Med Assoc J. 2009;11:453-5.

39. Chen M, Cortay J-C, Logan IR, Sapountzi V, Robson CN, Gerlier D. Inhibition of ubiqitination and stabilization of human ubiquitin E3 ligase PIRH2 by measles virus phosphoprotein. J Virol. 2005;79:11824-36.

40. Duan W, Gao L, Druhon LJ, Zhu WG, Morrison C, Otterson GA, Villalona-Calero MA. Expression of Pirh2, a newly identified ubiquitin protein ligase in lung cancer. J Natl Cancer Inst. 2004;96:1718-21.

41. Corcoran CA, Huang Y, Sheikh MS. The p53 paddy wagon: COP1, Pirh2 and MDM2 are found resisting apoptosis and growth arrest. Cancer Biol Ther 2004;3:721-5.

42. No authors listed: Increased transmission and outbreaks of measles, European Region, 2011. Wkly Epidemiol Rec. 2011;86:559-64.

43. Chen YT, Zheng T, Chou MC, Boyle P, Holford TR. The increase of Hodgkin's disease incidence among young adults. Experience in Connecticut, 1935-1992. Cancer. 1997;79:2209-18.

44. Liu S, Semenciw R, Waters C, Wen SW, Mao Y. Time trends and sex patterns in Hodgkin's disease incidence in Canada, 1970-1995. Can J Public Health. 2000;91:188-92. 